\title{
Identification of Chemical Compounds from Nipah (Nypa fruticans Wurmb.) Endosperm
}

\author{
Maria Dewi Astuti ${ }^{*}$, Khairatun Nisa ${ }^{1}$, Kamilia Mustikasari $^{1}$ \\ ${ }^{1}$ Department of Chemistry, Faculty of Mathematics and Natural Sciences Lambung Mangkurat University, \\ Jalan A. Yani km. 36 Banjarbaru, South Kalimantan, Indonesia
}

\begin{abstract}
The identification of chemical compounds in Nipah (Nypa fruticans Wurmb) endosperm has been done. The extraction of chemical compounds in Nipah endosperm has been done using the maceration method with heating and followed with absorbs-desorbs on active carbon given ethanol fraction. The result obtained was a brownish-yellow fraction. The phytochemical screening test did on endosperm and ethanol fraction. Phytochemical screening results showed that the Nipah endosperm contains phenolic, tannin, flavonoid, and saponin compounds, while the ethanol fraction of Nipah endosperm did not contain alkaloid, flavonoid, steroid, triterpenoid, phenolic, tannin, and saponin compounds. Based on UV-vis, IR, and GCMS spectra, the ethanol fraction contains of furfural compounds.
\end{abstract}

\section{Introduction}

Nypa fruticans Wurmb. or "Nipah" (in Banjarese, South Kalimantan) is a mangrove plant belonging to the Palmae family. This plant commonly found in the habitat areas or adjacent to the mangrove forests. The distribution of this plant in South Kalimantan, Indonesia covers the areas of Tanah Laut, Pulau Laut, Barito Kuala, Tanah Bumbu, and Banjar Regencies [1].

Traditionally "Nipah" plant has been used as firewood and broomsticks, as well as handicrafts. The fruits of this plant are the essential source of palm sugar, flour, and some processed foods. Some parts of "Nipah" are also used as traditional medicine, such as stomachaches, diabetes mellitus, fever-reducing, mouth ulcers, toothaches, and headaches [2].

The phytochemical screening shows that some parts of this plant contain bioactive compounds or secondary metabolites. For example, the Nipah root contained alkaloids, steroids, triterpenoids, flavonoids, and tannins [1]. The leaf crude extracts of this plant also contained several compounds, such as polyphenols, flavonoids, triterpenoids, steroids, saponins, and alkaloids [3]. The chemical compounds in Nipah fruits are chlorogenic acid, protocatechuic acid, and kaempferol [4]. Fiber analysis on palm fruit flour showed that crude palm fiber is $46.18 \%$ consisting of 63.03\% ADF (Acid Detergent Fiber), 83.01\% NDF (Neutral Detergent Fiber), 19.98\% hemicellulose, and $62.35 \%$ cellulose [5]. The objective of this study is to identify the chemical compounds in Nipah endosperm using chromatography (TLC and GC-MS), and spectrophotometry (UV-Vis).

\section{Materials And Methods}

\subsection{Plant Collections}

Nipah fruits were collected from the mangrove area at Tamban Muara Village Barito Kuala Regency, South Kalimantan.

\subsection{Preparation of Nipah Fruit}

Individual fruit was released from bunches. Then, the fruits were peeled to obtain the edible endosperm. The Nipah endosperms were dried in an oven, at a $60^{\circ} \mathrm{C}$ to a constant weight. The dry sample was then cooled and filtered using a sieve (20 mesh size). The dried powder was then extracted further.

\subsection{Sample Extraction}

Dry powder endosperm $(1 \mathrm{~kg})$ and distilled water were magnetically stirred for $30 \mathrm{~min}$ at $80^{\circ}$ in the dark. After cooling, the solution was vacuum filtered through celite $(1 \mathrm{~cm})$. The aqueous extract was adjusted to $\mathrm{pH}$ 3.0 with phosphoric acid, to which activated carbon at $40 \mathrm{~g} / \mathrm{L}$ was added, and magnetically stirred for 30 min at $60^{\circ} \mathrm{C}$, under dark. After cooling at room temperature, the mix was vacuum filtered through celite (1 cm). The chemical compounds were desorbed from activated carbon using ethanol $96 \%(\mathrm{v} / \mathrm{v})$, then dried with anhydrous sodium sulfate, and finally dried in a rotary evaporator at $60^{\circ} \mathrm{C}$, yielded ethanol fraction (Suarez-Quiroz et al., 2014).

\subsection{Phytochemical screening}

Phytochemical screening did on fresh endosperm and ethanol fractions of Nipah.

a. Alkaloid

Samples were added $2 \mathrm{~mL}$ chloroform, $2 \mathrm{~mL}$ ammonia, and 3 drops of concentrated $\mathrm{H}_{2} \mathrm{SO}_{4}$ then shaken and left for several minutes until formed two layers. The acid layer was taken, then Dragendorf reagents were added 4-5 drops. The formation of a yellow-red precipitate indicates the presence of alkaloids.

b.Flavonoid

Samples were added 2-5 $\mathrm{mL}$ of ethanol, then added $0.2 \mathrm{~g}$ of $\mathrm{Mg}$ powder and 3 drops of concentrated

Corresponding author: astuti_md17@yahoo.co.id 
$\mathrm{HCl}$. The formation of an orange-red color indicates the presence of flavonoid.

b. Steroid/triterpenoid test

Samples were added 2-5 $\mathrm{mL}$ chloroform, then added 10 drops of acetic anhydrate and 2 drops of concentrated $\mathrm{H}_{2} \mathrm{SO}_{4}$. The solution was shaken slowly and left for several minutes. Formation of either a blue or green color indicates the presence of steroid, while a red or purple for triterpenoid.

c. Phenolic/tannin

Samples were added 2-5 mL of ethanol, then added 3 drops of $1 \% \mathrm{FeCl}_{3}$ solution. Formation of the green, red, purple, blue, or deep black colors indicates phenolic compounds. The formation of a bluish-black color indicates the presence of tannin.

d. Saponin

Samples were added $3 \mathrm{~mL}$ of water while being shaken for 1 minute, then added 1-2 drops of $\mathrm{HCl} 2 \mathrm{~N}$. If the foam formed remained stable in \pm 7 minutes, then the positive extract contained saponin.

\subsection{Thin Layer Chromatography}

We used the TLC plates with a size of $1 \times 5 \mathrm{~cm}$ and at both ends were given a starting and ending a line with a distance of $0.5 \mathrm{~cm}$ from each end. $5 \mu \mathrm{L}$ of ethanol fraction was spotted at the start line. TLC plates were placed in a chamber containing chloroform. When the solvent reaches the end line, the plate was removed from the chamber and dried. The TLC plate was sawed under a UV lamp at $254 \mathrm{~nm}$. The TLC plate elution was repeated with other eluents such as ethyl acetate, nhexane, methanol, and toluene: ethyl acetate (9:1), as well as butanol: water: acetic acid with the ratio of $6: 2$ : 2 and $4: 5: 1$.

\subsection{Identification chemical compound of ethanol fraction using UV-Vis, IR spectrophotometer and GC-MS}

Ethanol fraction was dissolved with distilled water. The solution is put into a cuvette and its absorption was measured with spectrophotometer UV-Vis at wavelengths of 200 to $400 \mathrm{~nm}$.

Ethanol fraction was dripped on $\mathrm{KBr}$ crystal windowed infrared cells evenly, then measured $\%$ transmittance at $4000-400 \mathrm{~cm}^{-1}$ in IR spectrophotometer.

Ethanol fraction was analyzed using GC-MS Shimadzu QP 2010. A sample of $1 \mu \mathrm{L}$ was injected into GC-MS which was operated using an Rtx 5 MS column with a length of $30 \mathrm{~m}$, diameter $0.25 \mathrm{~mm}$, and thickness $0.25 \mu \mathrm{m}$. The oven temperature is programmed between $70-300{ }^{\circ} \mathrm{C}$ with a rate of temperature rise of $5^{\circ} \mathrm{C} /$ min, a Helium carrier gas pressure of $12 \mathrm{kPa}$, a total rate of $28 \mathrm{~mL} / \mathrm{min}$, and a split ratio of 1:50.

\section{Results And Discussion}

\subsection{Phytochemical Screening}

Phytochemical screening conducted in this study aims to determine the presence of several compounds, including alkaloids, flavonoids, triterpenoids, steroids, phenolics, and tannins, as well as saponins, both in the fresh and ethanol fraction of endosperm. Table 1 showed that fresh endosperm of Nipah contains the flavonoids, phenolics, tannins, and saponins. However, the ethanol fractions of this sample do not contain all of the compounds analyzed. It might be caused by the secondary metabolites not adsorbed on activated carbon during the extraction process. The existence of flavonoid and phenolics compounds in Nipah endosperm was parallel with Prasad et al. research [4].

Table 1. Phytochemical screening of fresh endosperms and ethanol fraction of Nipah.

\begin{tabular}{ccc}
\hline Phytochemical & Fresh & $\begin{array}{c}\text { Ethanol } \\
\text { fraction }\end{array}$ \\
\hline Alkaloid & - & - \\
Flavonoid & + & - \\
Steroid & - & - \\
Triterpenoid & - & - \\
Phenolic & + & - \\
Tannin & + & - \\
Saponin & + & - \\
\hline Note. (+) for positif result; (-) for negatif result
\end{tabular}

\subsection{Thin Layer Chromatography}

The compounds of ethanol fraction were performed by the thin layer chromatography (TLC) method. A TLC chromatogram of a single eluent fraction of Nipah fractions is shown in Figure 1.

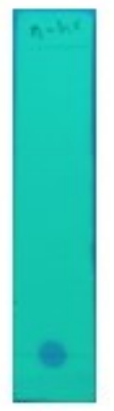

(a)

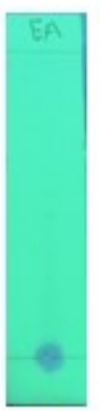

(b)

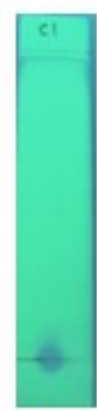

(c)

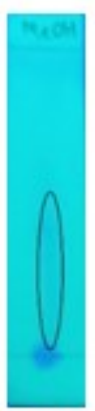

(d)
Figure 1. TLC chromatogram of ethanol fraction under UV-lamp $254 \mathrm{~nm}$ in single eluent, (a) n-hexane; (b) ethyl acetate; (c) chloroform; dan (d) methanol.

Figure 1 showed n-hexane, ethyl acetate, and chloroform eluents could not carry compounds in the sample on the TLC plate. The methanol eluent can separate compounds in the sample from the starting line 
up to half of the TLC plate length but can't separate the compounds well.

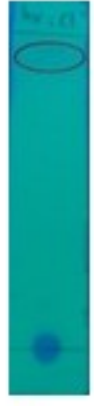

(a)

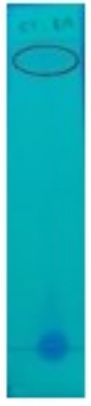

(b)

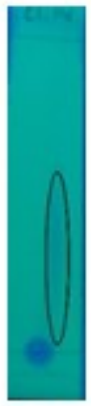

(c)

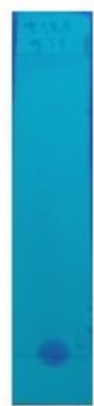

(d)

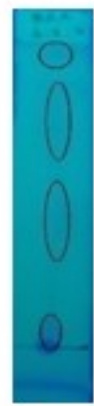

(e)

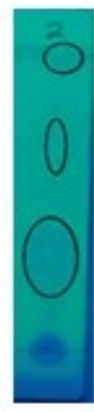

(f)
Figure 2. TLC Chromatogram of ethanol fraction under a UV lamp $254 \mathrm{~nm}$ in mix eluent, (a)

n-hexane:chloroform (1:1); (b) ethyl acetate:chloroform $1: 1$; (c) chloroform:methanol (1:1); (d) toluene:etyl acetate (9:1); (e) butanol:water:acetic acid (6:2:2); dan

(f) butanol:wateracetic acid (4:5:1)

Figure 2 showed the TLC chromatogram of ethanol fraction in many mixing eluent. The mixing of butanol: water: acetic acid (6: 2: 2) eluent (Figure 2.e) generate the best separation to the others, with 4 spots. This mixing solution (butanol: water: acetic acid) is widely used as a general TLC eluent to separate many classes of plant compounds [6].

\subsection{Identification of Chemical Compounds from Ethanol Fraction of Nipah Endosperm}

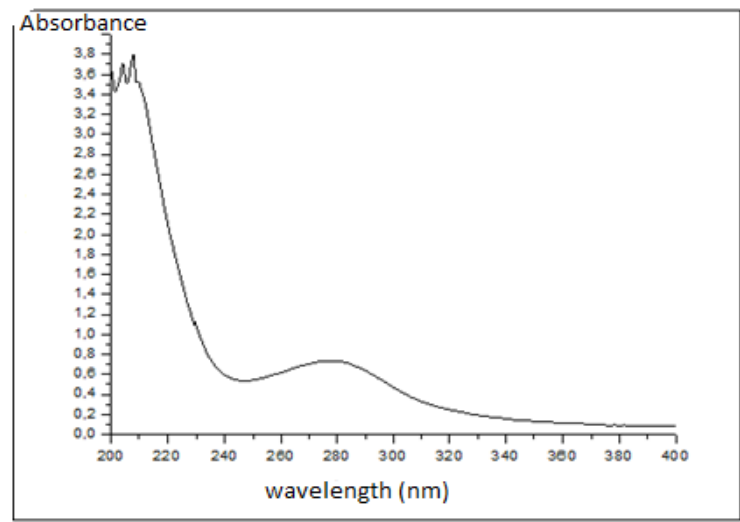

Figure 3. UV spectra of ethanol fraction.

Based on Figure 3, the UV spectra of ethanol fraction in distilled water have generated two peaks. The first peak has a maximum wavelength absorption of $277 \mathrm{~nm}$ with an absorbance value of 0.734 and the second peak has a maximum wavelength absorption of $208 \mathrm{~nm}$ with an absorbance of 3,793. A wavelength absorption of $277 \mathrm{~nm}$ showed an electron transition from $\pi \rightarrow \pi^{*}$ orbitals for a conjugated double bond system [7]. Absorption at $208 \mathrm{~nm}$ wavelength is thought to be an electron transition $n \rightarrow \sigma^{*}$ caused by a nonconjugated autochrome which absorbs light at a wavelength of about $200 \mathrm{~nm}$ which has a $-\mathrm{OH}$ group [8]. The study of Ardiana \& Mitarlis on Siwalan rind (Borassus flabellifer), the same family of Nipah fruit (Nypa fruticans), Arecaceae family, shows a wavelength of $277.43 \mathrm{~nm}$ which is to be a furfural compound [9].

IR spectra of ethanol fraction showed functional group vibration, such as $\mathrm{OH}, \mathrm{C}-\mathrm{H}$ aliphatic, carbonyl $(\mathrm{C}=\mathrm{O})$, and $\mathrm{C}-\mathrm{O}$ vibrations (Figure 4 and Table 2).

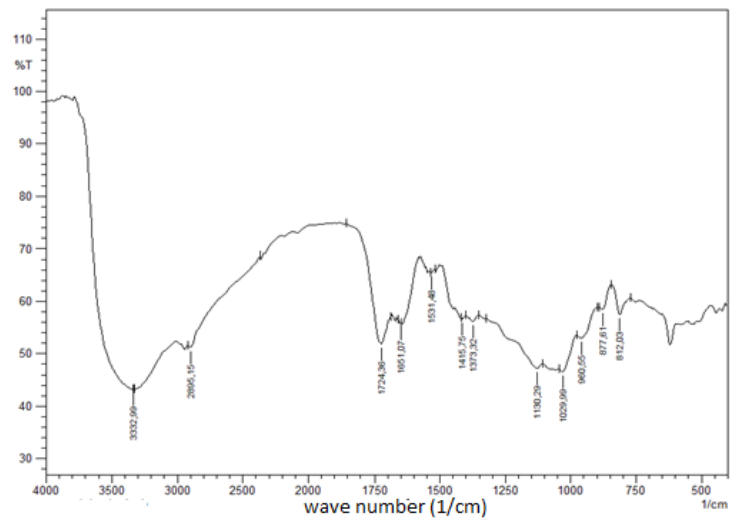

Figure 4. IR spectra of ethanol fraction.

Table 2. IR spectra data.

\begin{tabular}{cc}
\hline Wavenumber $(\mathrm{cm}-1)$ & Functional Group \\
\hline 3332.99 & $-\mathrm{OH}$ \\
2895.15 & $\mathrm{C}-\mathrm{H}$ aliphatic \\
1724.36 & $\mathrm{C}=\mathrm{O}$ \\
1651.07 and 1531.48 & $\mathrm{C}=\mathrm{C}$ \\
1130.29 & $\mathrm{C}-\mathrm{O}$ \\
3332.99 & $-\mathrm{OH}$ \\
\hline
\end{tabular}

There were several peaks on the GC chromatogram of ethanol fraction (Figure 5). It means ethanol fraction was not pure yet. The ethanol fraction contained several chemical compounds. Chemical compounds in ethanol fraction can be seen in Table 3. The highest $\%$ area values were peak 6 (42.27\%). The highest SI values are found at peaks 1 and 2 (SI value of 91). If the SI value approaches 100 it indicates that the identified compound is getting closer to the standard compound. Thus, the components of peak compounds 1 and 2 can be said to be almost the same as standard compounds, namely from the furfural group.

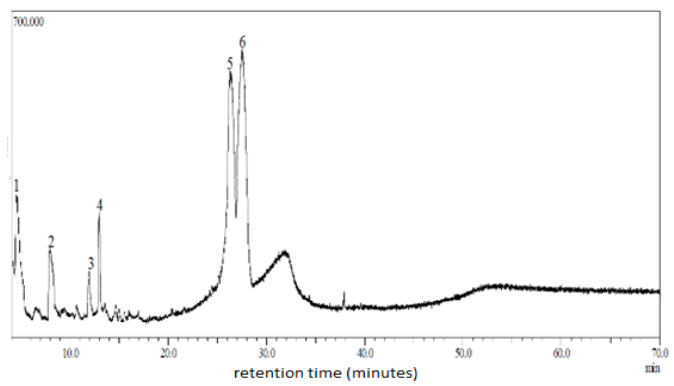

Figure 5. GC chromatogram of ethanol fraction 
Table 3. GC-MS analysis of ethanol fraction.

\begin{tabular}{cccccc}
\hline Peak & $\begin{array}{c}\text { Rt } \\
\text { (minutes) }\end{array}$ & Area (\%) & $\begin{array}{c}\text { Molecule } \\
\text { Relative }\left(\mathrm{M}^{+}\right)\end{array}$ & $\begin{array}{c}\text { Chemical compound } \\
\text { name }\end{array}$ & SI \\
\hline 1 & 4.594 & 8.19 & 96 & Furfural & 91 \\
2 & 7.945 & 5.99 & 110 & 5-metylfurfural & 91 \\
3 & 11.930 & 2.58 & 124 & 2-propanoilfuran & 76 \\
4 & 12.956 & 4.60 & 98 & Furfuril alcohol & 84 \\
5 & 26.355 & 36.38 & 242 & 2-metil-3-oktanol & 73 \\
6 & 27.515 & 42.27 & 224 & 5-metylfurfural & 72 \\
\hline
\end{tabular}

The presence of furfural compounds in ethanol fraction in Nipah fruit is caused by the presence of hemicellulose in Nipah. Hemicellulose was hydrolyzed into pentose sugar, then sugar pentose dehydrated and cyclization forms furfural due to reactions due to the addition of phosphoric acid and heating at the extraction process. The reaction to furfural formation can be seen in Figure 6.

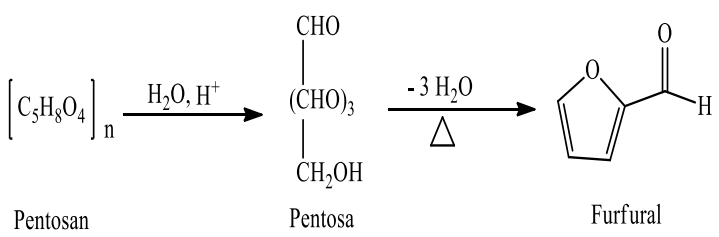

Figure 6. The reaction of furfural formed [10].

\section{Conclusion}

Phytochemical screening showed that Nipah endosperm contains phenolic, tannin, flavonoid, and saponin compounds, while the ethanol fraction of Nipah endosperm did not contain all compounds analyzed. Based on UV-vis, IR, and GC-MS analysis, the ethanol fraction of this sample contains of the furfural compounds.

\section{References}

1. R.R. Radam. \& E. Purnamasari. Jurnal Hutan Tropis. 4: 28-34, (2016)

2. Imra, K. Tarman \& Desniar. JPHPI. 19: 241-250, (2016)

3. Y. Lestari, P. Ardiningsih, \& Nurlina.. Jurnal Kimia Khatulistiwa. 5: 1-8., (2016)

4. N. Prasad, B. Yang, K.W. Kong, H.E. Khoo, J. Sun, A. Azlan, A. Ismail, \& Z.B. Ramli.1-9, (2013)

5. T. Dalming, Aliyah, Mufidah, V. Margareth, \& A. Asmawati. Media Farmasi. 14: 140-145, (2018)

6 M.L Suarez-Quiroz, A.A. Campos, G.V. Alfaro, O. Gonzalez-Rios, P. Villeneuve, \& M.C. FigueroaEspinoza.. Journal of Food Composition and Analysis. 33: 55-58, (2014)

7. J.B. Harborne. ITB. Bandung, (1987)

8. H. Sastrohamidjojo. Yogyakarta, (2001)

9. C. Creswell, O. Ruquist \& M. Campbell. Bandung, ITB, (2005)

10. R. Ardiana \& Mitarlis. UNESA Journal of Chemistry. 1: 69-74, (2012)

11. N. Hidajati. Jurnal Ilmu Dasar. 8: 45-53, (2006) 